\title{
RELATION BETWEEN NEGATIVE TONE IN NEWS RELEASES OF WHO AND INDUSTRY RETURNS DURING THE COVID-19 PANDEMIC
}

\section{Denada Ibrushi ${ }^{*}$ and Helmi Jedidi2}

1. Greehey School of Business, St. Mary's University, San Antonio Texas

2. Deloitte Montreal, Canada

* Corresponding Author: Denada Ibrushi, Assistant Professor of Finance, Greehey School of Business, St. Mary's University, 1 Camino Santa Maria San Antonio Texas, 78228

$\bowtie$ Email: dibrushi@stmarytx.edu

\begin{abstract}
We analyse the relationship between the negative tone in news releases issued by the WHO and industry returns during the COVID-19 pandemic. We construct our news tone measure as the ratio of negative words to the total number of words present in news releases of WHO. The news tone shows to be significantly associated with returns for the majority of industries. Bad news announced by the WHO translates into good news for consumer nondurables, telecommunications, and healthcare sectors. Negative tone in news releases of WHO is on average bad news for consumer durables, manufacturing, energy, and other industries. Our findings suggest that the news tone-return relation varies significantly throughout our COVID19 sample.
\end{abstract}

Keywords: News Tone; WHO; COVID-19; Industry returns.

\section{Introduction}

Stock markets plunged on March 1 1, 2020, as the World Health Organization (WHO) declared the rapidly spreading coronavirus a global pandemic. The Dow dropped by approximately 1,500 points after the WHO's announcement. The Standard \& Poor 500 closed at a $4.9 \%$ fall for the session. In a Washington Post article, Taylor and Heath (2020) report that industrials, financials, energy, and real estate were the sectors mainly affected by the pandemic announcement, while the health sector was least affected. While the pandemic announcement has been crucial in terms of its impact on financial markets across the globe, it is important to note that the WHO issued multiple news releases before as well as after the announcement of the global pandemic. Garcia (2013) underlines the importance of news arrival in resolving uncertainty during periods of economic recession by reporting that the impact of media pessimism on the Dow Jones index is three times higher in recession than in expansion. However, this last recession, because it resulted from a public health crisis, made everyone stay focused on one main organization: the WHO. A recent research report (Shearer, 2020) shows that $51 \%$ of U.S. adults consider public health organizations and officials a major source for news about the coronavirus outbreak. While the slow response of the WHO to the COVID-19 has been under criticism, Kuznetsova (2020) as well as a recent editorial of the Nature Microbiology stress the importance of the WHO in preventing and controlling global outbreaks. Both studies show that the WHO learned its lessons from coronavirus and with the right resources it will exhibit successful response to potential health threats. Consequently, in this article we seek to examine the impact of various news releases published on the WHO's website during the first seven months of 2020. More specifically, we 
analyze how the tone of these releases affects stock returns across twelve industry portfolios constructed by Professors Fama and French and available on Professor Kenneth French's website.

It has been widely discussed in literature the role that the tone of news plays in stock market reactions. In a recent paper, Ahmad et al. (2016) finds that during certain episodes the media tone has a temporary effect on firm returns and on others a permanent one. Tetlock (2007) asserts that tone in media includes new information about fundamental value, contributing to an important side of the literature (Groß-Klußmann and Hautsch, 2011; Loughran and McDonald, 2011; Dzielinski and Hasseltoft, 2013; Heston and Sinha, 2017) that documents a significant relationship between the negative tone in news and negative next-day returns. We contribute to a growing literature addressing the impact of news tone at different firm and market levels by measuring the negative news tone in WHO releases and studying its relation to industry returns during the COVID-19 pandemic. To the best of our knowledge, this is the first study to evaluate the negative tone (used interchangeably with news tone hereinafter) of news releases published by the WHO during the COVID-19 pandemic and relating it to sector returns.

In this paper, we first measure the tone of news releases available on the WHO's website during our COVID-19 sample period. We apply Natural Language Processing (NLP) techniques for our textual analysis and use the Loughran and McDonald (2011) dictionary as our benchmark to measure the proportion of negative words to the total number of words within a news release. We manually extend the pre-set group of words in the Loughran and McDonald (2011) dictionary to account for health-related terminology. On average, we observe 36 days with news releases that were published by the WHO and carry the "Coronavirus disease (COVID-19)" tag. May is the month with the highest number of articles whereas July and March are characterized by the most negative tone in news. The news tone for the whole sample period has a mean of $6.4 \%$ and standard deviation of $2.2 \%$. Constructing a measure of the news tone present in the WHO's news releases and studying its impact during the COVID-19 pandemic can help us understand better and resolve uncertainty during recessions of a public health nature.

Our findings show a significant relationship between the WHO's news tone and returns at the industry level. The consumer nondurables, telecommunications, and healthcare sectors react positively to increased negative news from the WHO. In contrast, consumer durables, manufacturing, energy, and other sectors are negatively related to its bad news. Financial companies remain resilient to negative news. Chemicals, shops, and business equipment industries are also not susceptible to negative news released by the WHO. It is worth noting that this article does not consider predictability patterns using lagged news tone measures. While this is an important exercise for future research as more data becomes available, at this phase it is optimal to focus on determining whether there is a significant relation in the first place. Last but not least, implementing the rolling window approach that is commonly applied in similar studies (Ahmad et al. (2016)), we observe that the impact of news tone on returns is not only significant for most of the industries but also varies throughout the COVID19 period. In agreement with Bianchi (2020), we also believe that rare events in previous periods affect investors' expectations and therefore we anticipate the COVID-19 pandemic to have a significant impact in determining investors' expectations even after the pandemic ends. Our results suggest that the WHO should be viewed as an important news source affecting stock returns.

\footnotetext{
1 www.who.int.
} 
Our paper complements the evolving literature that is investigating financial markets during the COVID-19 pandemic. Goodwell (2020) is one of the pioneers of the COVID-19 literature, contributing tremendously by providing guidance on potential topics that address the impact of the pandemic. Baker et al. (2020) use text-based methods in their study of stock market reaction during coronavirus versus previous pandemics. They find that government restrictions on commercial activity as well as social distancing are the prior reasons the U.S. stock market reacted strongly to COVID-19 than to previous virus outbreaks. Ramelli and Wagner (2020) is another interesting study demonstrating that the expected effects from COVID-19 are amplified through financial channels. Erdem (2020) identifies differences in the effects of COVID-19 news on stock indices in free versus non-free regimes. While Erdem uses the term "news," it does not refer to a direct news measure in a published text as is our case with WHO publications; he defines news as incoming data about the number of cases and deaths per million. Likewise, Haroon and Rizvi (2020) study how markets behave toward media coverage. They obtain their panic, sentiment, and media coverage indices externally and document that panic in news is related to higher volatility in stock markets. In another study, Ding et al. (2020) use Google trends related to COVID-19 to model market sentiment, a variable that we also estimate and use as a control variable in our specification. This article documents that the most digitally transformed industries remain resilient to negative sentiment in the market. He et al. (2020) also examines the impact of COVID-19 on different industries and report that the Chinese sectors more negatively affected are mining, transportation, electricity and heating, and the environment. Smales (2021) is another paper close to ours based on the heterogeneous impact of its attention variable across different sectors during the COVID-19 crisis. It is important to emphasize that the attention variable of this paper is equivalent to the COVID-19 attention variable that we include in our analysis as a control variable. Our article fortifies the argument that neither the COVID-19 attention variable nor our news tone sentiment from issued news articles of the WHO are the only factors affecting stock returns during the pandemic. More importantly, we show that our news tone variable exhibits a significant impact even when we control for the COVID-19 attention variable and that it affects distinct sectors differently. Motivated by this literature, we construct our measure for tone present in the WHO's news releases and study its impact on multiple industries over the span of the COVID-19 pandemic.

The rest of the paper is organized as follows. Section 2 describes the data and the steps we take to build the news tone measure. Section 3 provides methodology and results, and Section 4 shares conclusions and suggestions for future research.

\section{Building News Tone Measure and Data Description}

We apply Natural Language Processing (NLP) techniques to analyze the textual content of news releases issued by the WHO. We start by scraping the WHO website to retrieve the Hypertext Markup Language (HTML) elements for all news releases tagged with "Coronavirus disease (COVID-19)" in the WHO newsroom between January 1 and July 31, 2020. After gathering the text body of each news release, we continue with the following steps: i) tokenization, ii) expanding contractions, iii) removing stop words, iv) stemming and lemmatization, v) part-of-speech (POS) tagging, and vi) word classification. Tokenization consists of breaking down each news article into single words called tokens. We then expand the shortened versions of spoken forms of words so that they can be easily matched in the following steps. In the next step, punctuation, special characters, non-numerical characters as well as stop words are removed from the news article. This ensures mitigation of extra noise from unstructured texts. Stemming and lemmatization consist of reducing derivationally related words into their common root (lemma). Afterwards, we identify the grammatical grouping of tokens via POS tagging. Finally, we conduct sentiment (tone) analysis using text classification. The Loughran and McDonald (2011) financial sentiment dictionary serves as our 
benchmark to capture tone in WHO's news releases. Furthermore, we extend the Loughran and McDonald (2011) dictionary and its terminology by accounting also for pandemic context and health-related terms. We finally construct our news tone measure as the percentage of negative words to the total number of words present in a news article/s issued by the WHO within a day.

We obtain our daily Fama-French factors and industry return data from Professor Kenneth French's website. The market, size, and value factors are used as control variables in our regression analysis in Section 3. We also control for the change in "coronavirus" Google trends and denote this measure as the COVID-19 attention variable. The trend of search volume for the word "coronavirus" is based on global searches from Google trends analytics. The twelve industries included in this study are as follows: consumer nondurables (NoDur), consumer durables (Durbl), manufacturing (Manuf), energy (Enrgy), chemicals (Chems), business equipment (BusEq), telecommunications (Telcm), utilities (Utils), shops (Shops), healthcare (Hlth), financials (Money), and others (Other). Industry portfolios are built based on NYSE, AMEX, and NASDAQ stocks.

Table 1 presents the summary statistics of our negative news tone variable as well as the number of news articles issued on a monthly basis. Considering the constrained number of observations for the month of January, we report the descriptive statistics of January and February jointly. The second column reports the number of issued news articles. Ten news articles were issued in May, rendering it the month with the highest number of articles. April is the second month with 7 articles. Focusing on the statistics of news tone, we find that the proportion of negative words in the news articles of the WHO is highest in July and March. The lowest extent of negative tone in issued articles is observed in April. The median and standard deviation estimates are reported in the last two columns. The last row of Table 1 indicates that in total we have 36 news articles with an average negative tone of $6.40 \%$ and standard deviation of $2.22 \%$.

Table 1: Descriptive Statistics - News Articles and Negative Tone

\begin{tabular}{lccll}
\hline & News Articles & Mean & Median & St. dev. \\
\hline Jan and Feb & 5 & 0.0679 & 0.0619 & 0.0196 \\
March & 5 & 0.0694 & 0.0677 & 0.0211 \\
April & 7 & 0.0513 & 0.0482 & 0.0138 \\
May & 10 & 0.0664 & 0.0680 & 0.0182 \\
June & 5 & 0.0620 & 0.0590 & 0.0371 \\
July & 4 & 0.0714 & 0.0590 & 0.0301 \\
\hline Overall Sample & 36 & 0.0640 & 0.0614 & 0.0222 \\
\hline
\end{tabular}

Note: This table presents the number of news articles, mean, median, and standard deviation of negative tone for each month listed in the first column. Estimates for January and February are reported together due to the limited number of observations in January. The summary statistics for the overall sample are presented in the last row. The sample period is 1 January - 31 July 2020.

In Table 2, we display the summary statistics for the returns on the industry portfolios as well as our new COVID-19 attention variable. During our sample period, the durables sector witnesses the highest daily average return, approximately $30 \%$, while energy exhibits the worst, with an average of $-23 \%$. Durables and energy are also the most volatile sectors. Shops, consisting of wholesale and retail, along with healthcare, have the lowest standard deviations among all 
industries. The descriptive statistics for the COVID-19 attention variable are provided in the last row. The COVID-19 attention has a mean of $3.59 \%$ and standard deviation of $23.95 \%$.

Table 2: Descriptive Statistics - Industry Returns

\begin{tabular}{lrrr}
\hline & Mean & Median & St. dev. \\
\hline NoDur & -0.0036 & 0.0900 & 2.4217 \\
Durbl & 0.3022 & 0.3500 & 3.7583 \\
Manuf & -0.0286 & 0.0100 & 3.2534 \\
Enrgy & -0.2331 & -0.3000 & 4.3949 \\
Chems & 0.0410 & 0.1300 & 2.5460 \\
BusEq & 0.1783 & 0.4800 & 2.8779 \\
Telcm & -0.0156 & 0.1600 & 2.4197 \\
Utils & -0.0159 & 0.1300 & 3.0605 \\
Shops & 0.1623 & 0.2500 & 2.2705 \\
Hlth & 0.0656 & 0.0700 & 2.2893 \\
Money & -0.0702 & -0.0100 & 3.5400 \\
Other & -0.0103 & 0.2200 & 2.8526 \\
COVID-19 attention & 0.0359 & 0.0000 & 0.2395 \\
\hline
\end{tabular}

Note: This table presents mean, median, and standard deviation of returns for each industry listed in the first column. The COVID-19 attention variable is provided in the last row. The sample period is 1 January - 31 July 2020.

\section{Methodology and Results}

In this section, we explain the methodological framework and examine the relationship between our variable of interest, the negative news tone in WHO releases, and industry returns. In the same spirit as Ahmad et al. (2016), who use rolling vector autoregressive regressions to determine the impact of news tone at firm level at different points in time, we utilize rolling windows of 60-day observations to estimate the effect of news tone on sector returns. Considering the limited data availability, we choose 60 days to be our optimal window size that also includes a sufficient number of news releases. ${ }^{2}$ We thus have an average of 15.4 news releases per rolling window. Our regression sample starts with the first news release available, published on January 21.

For a rigorous analysis of the relationship between news tone and sector returns, we run a slightly revised version of Fama and French, including an additional control variable next to the systematic factors of market, size, and value. We thus include the market sentiment proxy captured by the change in our COVID-19 attention measure. We also look at other measures, such as change in the number of new cases and deaths and observe that they are highly correlated not only to each other but also to our attention variable. Moreover, our results in Table Al from the appendix section show that the main patterns indicating the impact of news tone continue to hold in the presence of a control variable for the new cases of COVID19. Considering the sample size, we do not include these two variables in our main specification. Unlike studies (Tetlock (2007) and Ferguson et al. (2015)) that exclude all dates with no news releases, we follow Ahmad et al. (2016) and set to zero the dates when no news

2 Our results remain qualitatively the same when trying rolling windows of 40 and 50 days. 
was announced by the WHO. These zero news dates lead to downward-biased coefficients in absolute value and lower probability of significant results. Having determined the optimal window size and the independent variables, we now estimate the following regression:

$$
\mathrm{R}_{\mathrm{j}, \mathrm{t}}=\alpha_{\mathrm{j}}+\beta_{\mathrm{MKT}, \mathrm{j}} \mathrm{MKT}_{\mathrm{t}}+\beta_{\mathrm{SMB}, \mathrm{j}} \mathrm{SMB}_{\mathrm{t}}+\beta_{\mathrm{HML}, \mathrm{j}} \mathrm{HML}_{\mathrm{t}}+\beta_{\mathrm{Att}, \mathrm{j}} \mathrm{Att}_{\mathrm{t}}+\beta_{\mathrm{Tone}_{\mathrm{j}}} \mathrm{Tone}_{\mathrm{t}}+\varepsilon_{\mathrm{t}}
$$

where $\mathrm{R}_{\mathrm{j}, \mathrm{t}}$ denotes returns in excess of the risk-free rate for industry $\mathrm{j}$ on day $\mathrm{t}$. MKT, SMB, and HML denote excess market return, size, and value Fama-French factors. Att is the change in COVID-19 attention variable, and Tone is our measure of negative news tone.

Table 3: Impact of News Tone on Different Industries

\begin{tabular}{lccccc}
\hline & $\boldsymbol{\beta}_{\boldsymbol{M K T}}$ & $\boldsymbol{\beta}_{\boldsymbol{S M B}}$ & $\boldsymbol{\beta}_{\boldsymbol{H M L}}$ & $\boldsymbol{\beta}_{\text {Att }}$ & $\boldsymbol{\beta}_{\text {Tone }}$ \\
\hline NoDur & $0.7921^{* * *}$ & $-0.0820^{* * *}$ & $0.1200^{* * *}$ & $0.4844^{* * *}$ & $3.1356^{* * *}$ \\
Durbl & $1.1246^{* * *}$ & $0.4083^{* * *}$ & $0.0940^{* * *}$ & $-1.7601^{* * *}$ & $-15.2432^{* * *}$ \\
Manuf & $1.0403^{* * *}$ & $0.0885^{* * *}$ & $0.4352^{* * *}$ & $1.0813^{* * *}$ & $-1.3179^{* * *}$ \\
Enrgy & $1.1702^{* * *}$ & $0.2738^{* * *}$ & $0.8041^{* * *}$ & $0.7207^{* * *}$ & $-10.6476^{* * *}$ \\
Chems & $0.8621^{* * *}$ & $-0.2170^{* * *}$ & $0.1596^{* * *}$ & $1.8222^{* * *}$ & -0.2439 \\
BusEq & $1.1161^{* * *}$ & $0.0057^{* * *}$ & $-0.3457^{* * *}$ & $-0.5854^{* * *}$ & -0.1171 \\
Telcm & $0.8076^{* * *}$ & $-0.0516^{* * *}$ & $0.1819^{* * *}$ & $0.6213^{* * *}$ & $5.4529^{* * *}$ \\
Utils & $0.9783^{* * *}$ & $-0.2799^{* * *}$ & $0.2034^{* * *}$ & $0.8898^{* * *}$ & $-0.8850^{* * *}$ \\
Shops & $0.8611^{* * *}$ & $0.0366^{* *}$ & $-0.2854^{* * *}$ & $-0.5902^{* * *}$ & $-0.1855^{* * *}$ \\
Hlth & $0.8965^{* * *}$ & $-0.0653^{* * *}$ & $-0.2484^{* * *}$ & $1.0423^{* * *}$ & $2.2015^{* * *}$ \\
Money & $1.0991^{* * *}$ & $-0.1040^{* * *}$ & $0.6255^{* * *}$ & $0.0533^{* * *}$ & $0.0114^{* * *}$ \\
Other & $0.9232^{* * *}$ & $0.2040^{* * *}$ & $0.2801^{* * *}$ & 0.0154 & $-2.3268^{* * *}$ \\
\hline
\end{tabular}

Note: This table presents the average factor loadings in Equation (1) for each industry listed in the first column. The coefficient estimates are obtained from 60-day rolling windows of observations during our sample period of 21 January $2020-31$ July 2020. $* * * * *$, and * indicate statistical significance at the $1 \%, 5 \%$, and $10 \%$ levels, respectively.

Table 3 presents results from Equation (1) to analyze the relationship between industry returns and news tone. On average, we find a significantly positive association between the WHO's news tone and returns for consumer nondurables, telecommunications, and healthcare sectors. A one-percent change in news tone is associated with approximately $5 \%$ higher returns for telecommunications, rendering it the most positively sensitive sector to the negative toning of news. The finance sector is also positively related to news tone but not at a significant level. In contrast, there is a negative relationship between news tone and returns for consumer durables, manufacturing, and energy. Consumer durables dominates, with a negative change of $15 \%$ in stock returns per percentage change in news tone. Utilities is also negatively affected but to a lower extent (-0.89\%). As expected, we observe a significantly negative impact of more negative news on the last "Other" category, which includes mines, construction, building materials, transportation, hotels, bus services, and entertainment. In unreported results, we also consider the 30 industries classified by Fama and French and it is evident that the main sectors driving the results for the "Other" category are those of hotels and transportation. The lack of significance for chemicals, business equipment, shops, and financials is an interesting finding indicating that those sectors are resilient to the toning of news by the WHO. Focusing on the economic importance of our results, we find that one standard deviation change in the news tone is associated with respective changes of $0.0696 \%, 0.1211 \%$, and $0.0489 \%$ for the non-durables, telecommunications, and healthcare, 
which are the sectors that demonstrate a positive significant relationship. On the other side, one standard deviation change in news tone is related to $0.3384 \%$ and $0.2364 \%$ change for durables and energy sectors. Varying between $0.0196 \%$ and $0.0517 \%$, the impact is much lower for manufacturing, utilities, and other sectors. It is important to emphasize that we do not claim to build a new systematic factor in addition to Fama-French factors. Our goal is to understand the value of tone in news issued by the WHO during biological recessions and how it relates to different sectors over the pandemic, while also controlling for market, size, value and COVID-19 attention factors.

Documenting that consumer durables and telecommunications are the two main sectors representing opposite relations between news tone and industry returns, we now focus on the time variation of this news tone-return relation for these two sectors during our COVID-19 sample. In Figure 1, we plot the t-statistics for consumer durables and telecommunications based on 60-day rolling windows with ending dates as shown on the horizontal axis. We observe varying magnitudes and significance levels for our coefficient estimates. Put differently, the impact of news tone not only differs across industries, but also exhibits variation across time. It is evident from Figure 1 that news tone and returns for these two highly affected sectors are significantly related for a large part of rolling regressions and more strongly so during the earlier periods. More precisely, the positive association between telecommunications and news tone occurs for all rolling regressions up to mid-June, showing that telecommunications exhibit significant results $59 \%$ of the time, more frequently than any other sector. Durables, on the other hand, show a significant relation $43 \%$ of the time with the highest significance reached at the window ending on April 23. The news tone reaches the peak of its impact on energy, the second most negatively affected sector, on June 12. For brevity, we only graph the patterns for the two main sectors affected inversely.

\section{Figure 1: Time Variation in t-Statistics}

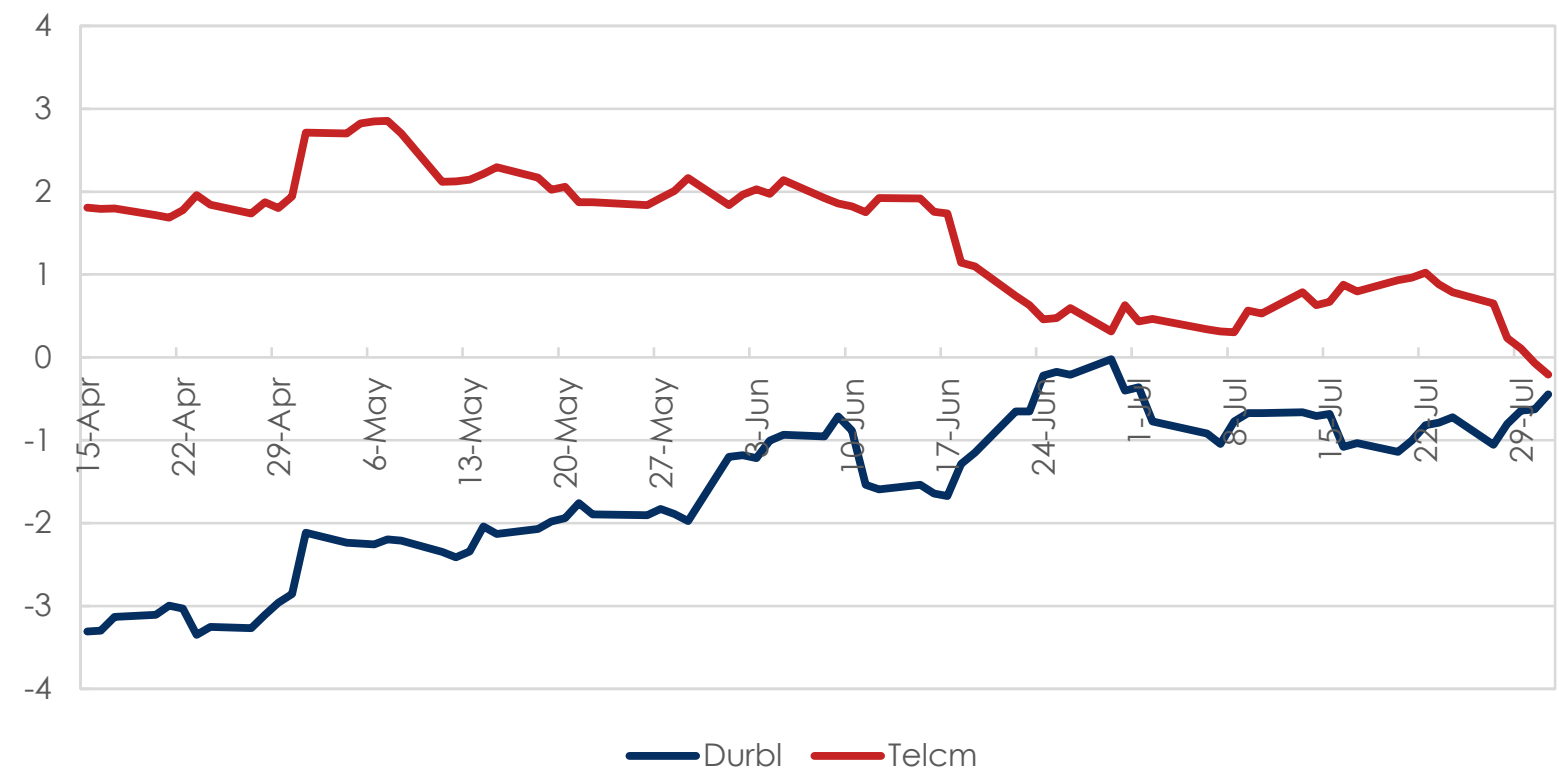

Note: This figure plots the t-test statistics for sectors of consumer durables and telecommunications based on each 60-day rolling window that ends on dates shown on the horizontal axis. Durbl (in blue) and Telcm (in red) represent durables and telecommunications sectors, respectively. The first rolling window ends on April 15 and the total sample utilized starts from 21 January to 31 July 2020. 
Overall, our results suggest that the tone of news releases from the WHO impacts most industry returns significantly. While more negative news issued by the WHO translates into bad news for consumer durables, manufacturing, energy, and other industries, it shows to be good news for consumer nondurables, telecommunications, and healthcare sectors. The effect of news tone varies in significance and magnitude across sectors and over time as well.

\section{Conclusion}

Tone in WHO news releases during the COVID-19 pandemic contains information for different industries. We add to the literature in three main ways. First, we conduct textual analysis to quantify the tone of news releases published by the WHO. Second, we show that our tone measure is significantly related to returns for the majority of industries and that various industries react differently to it. Third, the relation between news tone and industries exhibits variation throughout the COVID-19 period.

Finally, there are other directions worth researching in the future. For instance, there is value in checking for other forms of portfolio sorting, using either different firm characteristics or criteria such as ESG ranking. In addition, the relation between news tone and stock returns can have the opposite impact on individual firms within the same sector, making us observe solely the average of these individual effects at the sector level. Thus, it would be interesting to conduct a study at the firm level as more data becomes available. We also encourage future research to benefit from our work and replicate our approach to capture the importance of tone in the announcements of other organizations such as CDC (Centers for Disease Control and Prevention) during health-related crisis. Overall, as investors revise their expectations based on past recessions, it is important to thoroughly analyze WHO news releases as a major news source during and after a health crisis-triggered recession.

\section{References}

Ahmad, K., Han, J., Hutson, E., Kearney, C., Liu, S., 2016. Media-expressed negative tone and firm-level stock returns. Journal of Corporate Finance 37, 152-172.

Baker, S. R., Bloom, N., Davis, S. J, Kost, K., Sammon, M., Viratyosin, T., 2020. The unprecedented stock market reaction to COVID-19. Review of Asset Pricing Studies 10, 742758.

Bianchi, F., 2020. The Great Depression and the Great Recession: A view from financial markets. Journal of Monetary Economics 114, 240-261.

Ding, D., Guan, C., Chan, C. M., Liu, W., 2020. Building stock market resilience through digital transformation: Using Google trends to analyze the impact of COVID-19 pandemic. Frontiers of Business Research in China 14, 1-21.

Dzielinski, M., Hasseltoft, H., 2013. Aggregate news tone, stock returns, and volatility. University of Zurich, Working Paper.

Erdem, O., 2020. Freedom and stock market performance during COVID-19 outbreak. Finance Research Letters 36, Article 101671. 
Fama, E. F., French, K. R., 1993. Common risk factors in the returns on stocks and bonds. Journal of Financial Economics 33, 3-56.

Ferguson, N. J., Philip, D., Lam, H., Guo, J. M., 2015. Media content and stock returns: The predictive power of press. Multinational Finance Journal 19, 1-31.

Garcia, D., 2013. Sentiment during recessions. Journal of Finance 68, 1267-1300.

Goodell, J. W., 2020. COVID-19 and finance: Agendas for future research. Finance Research Letters 35, 101512.

Groß-Klußmann, A., Hautsch, N., 2011. When machines read the news: Using automated text analytics to quantify high frequency news-implied market reactions. Journal of Empirical Finance 18, 321-340.

Haroon, O., Rizvi, S. A. R., 2020. COVID-19: Media coverage and financial markets behaviorA sectoral inquiry. Journal of Behavioral and Experimental Finance 27, Article 100343.

He, P., Sun, Y., Zhang, Y., Li, T., 2020. COVID-19's impact on stock prices across different sectors-An event study based on the Chinese stock market. Emerging Markets Finance and Trade 56, 2198-2212.

Heston, S. L., Sinha, N. R., 2017. News vs. sentiment: Predicting stock returns from news stories. Financial Analysts Journal 73, 67-83.

Kuznetsova, L., .2020. COVID-19: The world community expects the World Health Organization to play a stronger leadership and coordination role in pandemics control. Front. Public Health. Available at https://doi.org/10.3389/fpubh.2020.00470.

Loughran, T., McDonald, B., 2011. When is a liability not a liability? Textual analysis, dictionaries, and 10-Ks. Journal of Finance 66, 35-65.

Ramelli, S., Wagner, A. F., 2020. Feverish stock price reactions to COVID-19. Review of Corporate Finance Studies 9, 622-655.

Shearer,E., 2020. Local news is playing an important role for Americans during COVID-19 outbreak. Available at https://www.pewresearch.org/fact-tank/2020/07/02/local-news-isplaying-an-important-role-for-americans-during-COVID-19-outbreak/.

Smales, L. A., 2021. Investor attention and the response of US stock market sectors to the COVID-19 crisis. Review of Behavioral Finance 13, 20-39.

Taylor T., Heath, T., 2020. Dow enters bear market after coronavirus declared pandemic. Available at https://www.washingtonpost.com/business/2020/03/11/markets-economytoday-oil-coronavirus/.

Tetlock, P. C., 2007. Giving content to investor sentiment: The role of media in the stock market. Journal of Finance 62, 1139-1168.

What has the World Health Organization done for us? Nat Microbiol 5, 977 (2020). Available at https://doi.org/10.1038/s41564-020-0772-3. 


\section{Appendix}

Table A.1: Impact of News Tone and new COVID-19 Cases on Different Industries

\begin{tabular}{|c|c|c|c|c|c|c|}
\hline & $\beta_{M K T}$ & $\beta_{S M B}$ & $\beta_{H M L}$ & $\beta_{\text {Att }}$ & $\boldsymbol{\beta}_{N C}$ & $\beta_{\text {Tone }}$ \\
\hline NoDur & $0.7937^{* * *}$ & $-0.0871 * * *$ & $0.1228 * * *$ & $0.5462 * * *$ & $-0.2680 * * *$ & $3.3545^{* * *}$ \\
\hline Durbl & $1.1360 * * *$ & $0.3908 * * *$ & $0.0988 * * *$ & $-1.7468 * * *$ & $-0.5986 * * *$ & $-14.9096 * * *$ \\
\hline Manuf & $1.0408^{* * *}$ & $0.0791 * * *$ & $0.4434^{* * *}$ & $1.2492 * * *$ & $-0.5887^{* * *}$ & $-1.0538 * * *$ \\
\hline Enrgy & $1.1712^{* * *}$ & $0.2678 * * *$ & $0.8079 * * *$ & $0.7759 * * *$ & $-0.2648 * * *$ & $-10.4753^{* * *}$ \\
\hline Chems & $0.8621^{* * *}$ & $-0.2175^{* * *}$ & $0.1600^{* * *}$ & $1.8326^{* * *}$ & -0.0251 & -0.2414 \\
\hline BusEq & $1.1145^{* * *}$ & $0.0087 *$ & $-0.3467 * * *$ & $-0.6060 * * *$ & $0.1167^{* * *}$ & -0.2233 \\
\hline Telcm & $0.8073^{* * *}$ & $-0.0394^{* * *}$ & $0.1708 * * *$ & $0.4143^{* * *}$ & $0.7419^{* * *}$ & 5.2102 *** \\
\hline Utils & $0.9814^{* * *}$ & $-0.2795 * * *$ & $0.1995^{* * *}$ & $0.8134^{* * *}$ & $0.1913^{* * *}$ & $-0.8909 * * *$ \\
\hline Shops & $0.8597^{* * *}$ & $0.0376 * *$ & $-0.2847^{* * *}$ & $-0.5810^{* * *}$ & 0.0003 & $-0.2483 *$ \\
\hline Hlth & $0.8949 * * *$ & $-0.0638 * * *$ & $-0.2482 * * *$ & $1.0670 * * *$ & 0.0108 & $2.2084^{* * *}$ \\
\hline Money & $1.1005^{* * *}$ & $-0.1050 * * *$ & $0.6253^{* * *}$ & 0.0449 & -0.0027 & -0.0029 \\
\hline Other & $0.9243^{* * *}$ & $0.1974^{* * *}$ & $0.2848 * * *$ & $0.1065^{* *}$ & $-0.3524^{* * *}$ & $-2.0983 * * *$ \\
\hline
\end{tabular}

Note: This table presents for each industry listed in the first column the average factor loadings from the following revised version of Equation (1). In addition to the Fama and French factors, attention, and news tone variables, the coefficient estimates for change in new COVID-19 cases, denoted by NC, are also included. The coefficient estimates are obtained from 60-day rolling windows of observations during our sample period of 21 January 2020 - 31 July 2020. ${ }^{* *},{ }^{* *}$, and ${ }^{*}$ indicate statistical significance at the $1 \%, 5 \%$, and $10 \%$ levels, respectively.

$$
\mathrm{R}_{\mathrm{j}, \mathrm{t}}=\alpha_{\mathrm{j}}+\beta_{\mathrm{MKT}, \mathrm{j}} \mathrm{MKT}_{\mathrm{t}}+\beta_{\mathrm{SMB}, \mathrm{j}} \mathrm{SMB}_{\mathrm{t}}+\beta_{\mathrm{HML}, \mathrm{j}} \mathrm{HML}_{\mathrm{t}}+\beta_{\mathrm{Att}, \mathrm{j}} \mathrm{Att}_{\mathrm{t}}+\beta_{\mathrm{NC}, \mathrm{j}} \mathrm{NC}_{\mathrm{t}}+\beta_{\mathrm{Tone}, \mathrm{j}} \text { Tone }_{\mathrm{t}}+\varepsilon_{\mathrm{t}}
$$

